\title{
EFFECT OF VITAMIN D SUPPLEMENTATION IN HIGH DOSES ON CARDIAC FUNCTION IN HEMODIALYSIS PATIENTS
}

\author{
By
${ }^{1}$ Hossam Mahmoud Abd El-Razik El-Sayed, ${ }^{1}$ Ahmed Alaa El-Din Ahmed Saad, ${ }^{2}$ Nabil Fathy Esmael Hasan and ${ }^{1}$ Mohamed Ahmed El-Sayed \\ Ahmed \\ ${ }^{1}$ Department of Internal Medicine \& Nephrology, Faculty of Medicine, Al-Azhar \\ University \\ ${ }^{2}$ Department of Clinical Pathology, Faculty of Medicine, Al-Azhar University \\ Corresponding author: Hossam Mahmoud Abd El-Razik El-Sayed,
}

Mobile: 01009735900

\begin{abstract}
Background: The overall cost of CKD accounts for 1.3\% of health care budgets of which $13 \%$ is related to the excess myocardial infarctions and strokes associated with CKD.

Objective: To assess the effect of native vitamin D supplementation in high doses on cardiac functions in hemodialysis (HD) patients.

Patients and Methods: This was a prospective cohort study which done in Kobry Elkobba Military Hospital conducted from June to September 2020 on 50 regular hemodialysis patients for > 6 months; to assess the effect of native vitamin D supplementation in high doses on cardiac functions in hemodialysis (HD) patients.

Results: Multiple regression analysis showed that after applying (Forward method) and entering some predictor variables the increase in baseline TGs; and the decrease in vitamin D level; had an independent effect on increasing follow-up (3-months) LVMI; with significant statistical difference ( $p<0.05$ respectively). Logistic regression analysis shows that; after applying (Forward method) and entering some predictor variables; the increase in Vitamin D level; had an independent effect on increasing the probability of EF improvement occurrence; with significant statistical difference $(\mathrm{p}=0.0005)$.
\end{abstract}

Conclusion: Vitamin D played a pivotal role in uremic CVD and its supplementation should be considered even in the absence of mineral metabolism disorders, after hypovitaminosis is detected.

Keywords: Chronic kidney disease, cardiovascular, hemodialysis.

\section{INTRODUCTION}

Chronic kidney disease (CKD) is a global health burden estimated to affect up to $15 \%$ of adult populations and is independently associated with increased cardiovascular (CV) disease risk similar to the risk of diabetes mellitus or coronary heart disease. This risk increases as CKD advances and is evidenced by worsening excretory function, usually manifest as declining glomerular filtration rate, and increasing proteinuria. The overall cost of CKD accounts for $1.3 \%$ of health care budgets of which $13 \%$ is related to the excess myocardial infarctions and strokes associated with CKD (Major et al., 2018). 
Several studies have demonstrated that individuals with CKD are at high risk of vitamin D deficiency (VDD). FernándezRuiz et al. (2018) reported that $97 \%$ of the patients on hemodialysis presented inadequate levels of 25(OH)-VD.

In a cross-sectional analysis of a cohort study including 1056 United States dialysis units showed that $79 \%$ and $57 \%$ out of 908 individuals on chronic hemodialysis (HD) had 25(OH)-VD levels of $<30$ and $<20 \mathrm{ng} / \mathrm{mL}$, respectively (Bhan et al., 2018).

Vitamin D appears to play a more extensive role as a cell differentiates and ant proliferative factor with actions in a variety of tissues including the renal, cardiovascular, and immune systems. As new evidence has improved our understanding of classical, as well as the non-classical, functions for vitamin $\mathrm{D}$, it has become apparent that the autocrine role of vitamin $\mathrm{D}$ is an important modulator of several systems including the immune, renal and cardiovascular systems (Umar et al., 2018).

In patients with CKD, the new nonclassical role of vitamin $\mathrm{D}$ also encompasses regulation of the reninangiotensin system (RAS) and the nuclear factor (NF). These emerging findings establish a new paradigm in approaching treatment to address both the classical and non-classical effects of vitamin $D$ in patients affected by vitamin D deficiency, particularly those with CKD (Kim and Kim., 2014).

Meta-analyses of observational studies have suggested that vitamin D supplementation in CKD patients improves mortality, including cardiovascular mortality. However, randomized controlled trials (RCTs) evaluating the utility of vitamin D supplementation in improving surrogate markers of cardiovascular structure and function remain inconclusive. In many cases, the interventional dose has been kept low in fear of developing hypercalcemia, which is uncommon. Thus, vitamin D levels in study participants did not rise significantly, which may explain the negative findings. Furthermore, the uses of different vitamin D formulations limit the ability to compare improvements in overall vitamin D status between studies. Meanwhile, there are no completed RCTs that are appropriately designed to evaluate the impact of vitamin D supplementation on hard end-points in CKD (Junarta et al., 2019).

The present work aimed to assess the effect of native vitamin D supplementation in high doses on cardiac functions in hemodialysis (HD) patients.

\section{PATIENTS AND METHODS}

Design: Prospective, cohort study.

Setting: Kubry El Qubba Military Hospital.

Study duration: 3 months.

Patients: A total of 50 regular hemodialysis patients for $>6$ months will be enrolled in the study.

Inclusion criteria: Patient's age $>18$ years and $<60$ years. Patients on hemodialysis $>6$ months and patients with Ejection fraction by echocardiography is less than $45 \%$.

Exclusion criteria: Severely anemic patients (Hemoglobin $<7 \mathrm{gm} / \mathrm{ml}$ ), Patients with valvular heart diseases, patients with 
congenital heart diseases, ischemic heart diseases: excluded by ECG, patients who had any malignancy, patients on regular hemodialysis < 6 months. Hypercalcemic patients and hyperphosphatemic patients.

\section{Methods:}

All patients have received oral vitamin D2 (ergocalciferol) 10000 IU daily for three months.

All patients have been subjected to history taking. Clinical examination including measurement of mean arterial blood pressure, weight, height, Body Mass Index (BMI) and evidence of heart failure. Laboratory work-up: Blood samples have been collected pre-dialysis at the start and after 3 months of the study for assessment of the following: Serum vitamin D2 level (25 hydroxycholecalciferol). Complete Blood Count (CBC). Serum creatinine, blood urea. Fasting blood glucose. Lipid profile (serum triglycerides, cholesterol, HDL and LDL). C-reactive protein (CRP).
Serum calcium and phosphorus. iPTH (intact Parathyroid Hormone).

The nature of the present study and laboratory or radiological procedures was explained to all participants. Consent was obtained from all participants. At the end of the study, all patients were informed about the results of the examinations performed, received appropriate recommendations and treatment.

\section{Statistical Methodology:}

Data entry, processing and statistical analysis were carried out using MedCalc ver. 18.11.3 (MedCalc, Ostend, Belgium). Tests of significance (Wilcoxon's, McNemar's tests, logistic and multiple regression analysis and Spearman's correlation were used. Data were presented as median (IOR) for quantative data and as number and percentage fpr qualitative data. P-values less than 0.05 $(5 \%)$ was considered to be statistically significant.

\section{RESULTS}

Regarding outcome data, $26 \%$ of patients had EF improvement (Table 1).

Table (1): Outcome data among 50 HD patients

\begin{tabular}{|l|c|}
\hline Variables & Frequency (\%) \\
\hline $\begin{array}{l}\text { EF improvement } \\
\text { (follow up EF > baseline EF) }\end{array}$ & $\mathbf{2 6 ( 5 2 \% )}$ \\
\hline
\end{tabular}

Comparative study between baseline and follow-up (3-months) assessment revealed, highly significant decrease in phosphorus and PTH, in HD patients ( $\mathrm{p}<$ 0.01 respectively).Comparative study between baseline and follow-up (3months) assessment revealed, highly significant increase in calcium, and vitamin $\mathrm{D}$ level in HD patients ( $\mathrm{p}<$ 0.0001).Comparative study between baseline and follow-up (3-months) assessment revealed, non-significant difference in hemoglobin, platelets, TLC, urea, creatinine, FBS, total cholesterol, TGs, HDL, LDL and CRP in HD patients ( $p>0.05$ respectively) (Table 2 ). 
Table (2): Comparison between 50 HD patients as regards serial echocardiographic assessments

\begin{tabular}{|c|c|c|c|}
\hline \multirow{2}{*}{ Variables } & $\begin{array}{c}\text { Baseline } \\
\text { Assessment n=50 }\end{array}$ & $\begin{array}{c}\text { Follow-up 3- } \\
\text { months assessment } \\
\text { n=50 }\end{array}$ & $\begin{array}{c}\text { Wilcoxon's } \\
\text { test }\end{array}$ \\
\cline { 2 - 4 } & Median (IQR) & Median (IQR) & P value \\
\hline LVESD $(\mathrm{mm})$ & $34.5(33-36)$ & $34(32-35)$ & $=0.6860$ \\
\hline LVEDD $(\mathrm{mm})$ & $54(51-57)$ & $55.5(52-57)$ & $=0.1425$ \\
\hline FS $(\%)$ & $38(35-40)$ & $38.5(36-40)$ & $=0.0003$ \\
\hline EF $(\%)$ & $41(39-43)$ & $44(40-47)$ & $=0.0006$ \\
\hline LVMI $\left(\mathrm{gm} / \mathrm{m}^{2}\right)$ & $\mathbf{1 2 7 . 5 ( 1 1 8 - 1 4 0 )}$ & $\mathbf{1 0 1}(\mathbf{9 5}-\mathbf{1 1 2})$ & $<\mathbf{0 . 0 0 0 1}$ \\
\hline Assessment & $\begin{array}{c}\text { Baseline } \\
\text { Assessment }\end{array}$ & $\begin{array}{c}\text { Follow-up 3- } \\
\text { months assessment }\end{array}$ & $\begin{array}{c}\text { McNemar's } \\
\text { test }\end{array}$ \\
\cline { 2 - 4 } & $\mathbf{+ v e}$ & $\mathbf{+ v e}$ & P value \\
\hline Variables & $16(32 \%)$ & $14(28 \%)$ & $=0.5000$ \\
\hline Valvular calcification & & &
\end{tabular}

Spearman's correlation analysis showed that; total cholesterol, and TGs, had a significant positive correlation with follow-up (3-months) LVMI (p < 0.05).Spearman's correlation analysis shows that; vitamin D level and PTH, had a significant negative correlation with follow-up (3-months) LVMI (p < 0.05).Spearman's correlation analysis shows that; all baseline laboratory variables had a non-significant correlation with follow-up (3-months) LVMI ( $\mathrm{p}>$ 0.05) (Table 3).

Table (3): Spearman's correlation analysis for clinical / laboratory Factors associated with follow-up (3-months) LVMI

\begin{tabular}{|l|c|c|}
\hline Follow up LVMI & R & P \\
\hline Hb $(\mathrm{g} / \mathrm{dL})$ & 0.130 & 0.130 \\
\hline PLT $\left(10^{3} / \mu \mathrm{L}\right)$ & -0.210 & $=0.1441$ \\
\hline TLC $\left(10^{3} / \mu \mathrm{L}\right)$ & -0.127 & $=0.3796$ \\
\hline Urea $(\mathrm{mg} / \mathrm{dL})$ & -0.0809 & $=0.5767$ \\
\hline Creat. $(\mathrm{mg} / \mathrm{dL})$ & -0.0822 & $=0.5702$ \\
\hline Ca $(\mathrm{mg} / \mathrm{dL})$ & 0.118 & $=0.4161$ \\
\hline Ph $(\mathrm{mEq} / \mathrm{L})$ & -0.179 & $=0.2142$ \\
\hline PTH $(\mathrm{pg} / \mathrm{m})$ & -0.302 & $=0.033$ \\
\hline FBS $(\mathrm{mg} / \mathrm{dL})$ & 0.0109 & $=0.9400$ \\
\hline T. Cholesterol $(\mathrm{mg} / \mathrm{dL})$ & 0.287 & $=0.043$ \\
\hline TGs $(\mathrm{mg} / \mathrm{dL})$ & 0.431 & $=0.0018$ \\
\hline HDL $(\mathrm{mg} / \mathrm{dL})$ & -0.0165 & $=0.9095$ \\
\hline LDL $(\mathrm{mg} / \mathrm{dL})$ & -0.161 & -0.161 \\
\hline CRP $(\mathrm{mg} / \mathrm{dL})$ & -0.00346 & $=0.9810$ \\
\hline Vitamin D level $(\mathrm{pg} / \mathrm{mL})$ & $\mathbf{- 0 . 3 1 4}$ & $\mathbf{0 . 0 2 6}$ \\
\hline
\end{tabular}

r: Spearman's r (correlation coefficient). 
Multiple regression analysis shows that; after applying (Forward method) and entering some predictor variables; the increase in baseline TGs; and the decrease in vitamin D level; had an independent effect on increasing follow-up (3-months) LVMI; with significant statistical difference $(\mathrm{p}<0.05$ respectively) (Table 4).

Table (4): Multiple regression model for the Factors affecting follow-up (3-months) LVMI using Forward method

\begin{tabular}{|c|c|c|c|}
\hline Predictor Factor & $\boldsymbol{\beta}$ & SE & P \\
\hline (Constant) & 108.1108 & & \\
\hline TGs & 0.08382 & 0.04116 & 0.047 \\
\hline Vit D level & -0.3167 & 0.1615 & 0.005 \\
\hline
\end{tabular}

Other factors excluded from the model as $\mathrm{p}$ value $>0.1$--- $\beta$ : Regression coefficient, SE: Standard error.

Logistic regression analysis shows that; after applying (Forward method) and entering some predictor variables; the increase in Vitamin D level; had an independent effect on increasing the probability of EF improvement occurrence; with significant statistical difference $(p=0.0005)$ (Table 5).

Table (5): Logistic regression model for the Factors affecting EF improvement occurrence using Forward method

\begin{tabular}{|c|c|c|c|}
\hline Predictor Factor & Coefficient & OR & P value \\
\hline (Constant) & -5.99320 & & \\
\hline Vitamin D level & 0.15116 & 1.1632 & 0.0005 \\
\hline
\end{tabular}

Other factors excluded from the model as ( $\mathrm{p}$ value > 0.1 ). OR: odds ratio.

\section{DISCUSSION}

Drechsler et al 2010 reported that, in the study population $54 \%$ of the patients were male. In general, the median (interquartile) level of $25(\mathrm{OH}) \mathrm{D}$ at baseline was $39 \mathrm{nmol} / \mathrm{L}$ (28-55).

Comparative study between baseline and follow-up (3-months) assessment revealed, highly significant increase in calcium, and vitamin $\mathrm{D}$ level in HD patients ( $\mathrm{p}<0.0001)$. Which came in agreement with Bucharles et al. (2012) and Miskulin et al. (2016).

Miskulin et al. (2016) reported that the proportion of patients with a serum $25(\mathrm{OH}) \mathrm{D}=30 \mathrm{ng} / \mathrm{ml}$ at 0,3 , and 6 months, respectively, were $1.5 \%, 78.9 \%$, and $67.5 \%$ in the ergocalciferol arm, $2.2 \%, 3.7 \%$, and $6.1 \%$ in the placebo arm.

Wang et al. (2016) reported that, $\mathrm{OH}$ ) $\mathrm{D}$, (VD2 + VD3)], nutrient indexes (plasma albumin, Pre albumin, and BMI), inflammatory biomarker (HsCRP), and the new comorbidity. After treatment, the mean plasma $\mathrm{Ca}$ and $\mathrm{P}$ levels remained well within the normal ranges. $\mathrm{iPTH}$ levels decreased more significantly in the test group versus the control group. Plasma 25(OH)D levels increased more significantly in the test group.

Comparative study between baseline and follow-up (3-months) assessment revealed, significant increase in FS and $\mathrm{EF}$ in HD patients respectively, which came in agreement with Pun et al. (2011), 
Bucharles et al. (2012) and Pecoits-Filho et al. (2012).

Bucharles et al. (2012) reported that, $\mathrm{LVH}$ is the most frequent cardiovascular abnormality in HD patients and is a strong predictor of mortality in this population. The pathogenesis of LVH has been extensively studied in uraemia, and although traditional risk factors such as fluid overload, hypertension, and anemia are involved, they cannot fully explain the changes observed in the uremic myocardium.

Pecoits-Filho et al. (2012) reported that, HF is also an important cause of morbidity and mortality in this population. Diastolic heart failure (DHF), also called HF with preserved ejection fraction, refers to a clinical syndrome in which patients have symptoms and signs of $\mathrm{HF}$, normal or near normal left ventricular (LV) systolic function, and evidence of diastolic dysfunction (e.g., abnormal LV filling and elevated filling pressure). Recent data suggest that HF with normal ejection fraction is even more common in patients than HF with low ejection fraction, including those on hemodialysis.

Comparative study between baseline and follow-up (3-months) assessment revealed significant decrease in LVMI in HD patients which came in agreement with Gluba-Brzózka et al. (2018).

Gluba-Brzózka et al. (2018) reported that, vitamin D deficiency promoted myocardial hypertrophy, greater heart weight/body weight ratio and extracellular matrix production in myocardial tissue, while administration of 1, 25dihydroxyvitamin D3 inhibited cell proliferation of primary ventricular myocytes. These observations were confirmed in hemodialysis patients, in whom vitamin D therapy (calcitriol) was associated with the reduction of left ventricle hypertrophy (LVH) accompanied by a considerable decrease in plasma renin activity and plasma angiotensin II levels.

We found marked increase in vitamin D level in improved group compared to not improved group during the serial baseline and follow-up (3-months) assessments which came in agreement with Jean et al. (2017). They reported that, Vitamin D insufficiency, which involves both serum $25(\mathrm{OH}) \mathrm{D}$ and 1 , $25(\mathrm{OH}) \mathrm{D}$ levels, is generally observed in CKD and dialysis patients. The main consequence is SHPT, and vitamin D compounds remain the first-line therapy for its prevention and treatment. Morbidity and mortality rates are associated with $25(\mathrm{OH}) \mathrm{D}$ insufficiency in CKD patients, but only VDRAs have been associated with better outcomes in large observational cohorts. Some questions remain unanswered about indication for serum vitamin D $(25(\mathrm{OH}) \mathrm{D}$ and $1,25(\mathrm{OH}) 2 \mathrm{D})$ measurements and about the real impact of these therapies on outcomes.

Spearman's correlation analysis showed that; vitamin D level and PTH, had a significant negative correlation with follow-up (3-months) LVMI which came in agreement with Bucharles et al. (2012) and Pecoits-Filho et al. (2012).

Bucharles et al. (2012) reported that LVMI was significantly reduced at the end of supplementation.

Matias et al. (2010) reported that, Vitamin $\mathrm{D}$ is also important in the regulation of BP through inhibition of the 
renin-angiotensin pathway, and lower circulating vitamin D levels correlated with increased BP and LVMI. Our study has shown that the correction of vitamin D deficiency with vitamin D precursors, namely cholecalciferol, can decrease LVMI. This reduction in BNP plasma levels and LVMI with supplementation was independent of PP and of the use of antihypertensive therapy, namely ACEIs and ARBs, and statins.

Pecoits-Filho et al. (2012) reported that, in patients with secondary hyperparathyroidism on hemodialysis, intravenous calcitriol caused regression in myocardial hypertrophy, as well as improved cardiac systolic and diastolic function. Indeed, vitamin D deficiency is highly prevalent among the dialysis and non-dialysis population and its supplementation with cholecalciferol is associated with a reduction in LVMI and attenuation of systemic inflammation.

Multiple regression analysis showed that after applying (Forward method) and entering some predictor variables; the increase in baseline TGs, decrease in vitamin D level; had an independent effect on increasing follow-up (3-months) LVMI; with significant statistical difference. This came in agreement with Drechsler et al. (2010), Wang et al. (2010), Bucharles et al. (2012), and Mose et al. (2014).

Wang et al. (2010) investigated the effect of vitamin D supplements added to calcium supplements Compared with women assigned to receive vitamin D placebo plus calcium supplementation, those assigned to both vitamin D and calcium supplementation had lower rates of ischaemic heart disease $(1.3 \%$ vs.
$2.0 \%)$ but similar rates of stroke $(2.0 \%$ for both).

Bucharles et al. (2012) reported that, CVD is the main cause of death in CKD patients, and many traditional and nontraditional risk factors, including disturbances of mineral metabolism, are involved in the pathogenesis of CVD in uremia. In the present study, we observed that HD patients with hypovitaminosis D and low iPTH levels presented with a reduction in biomarkers of inflammation and in LVMI after 6 months of supplementation with cholecalciferol. Hypovitaminosis D potentially plays a significant role in the myocardiopathy related to, ESRD as 1, 25(OH)2D acts as a negative regulator of renin-angiotensin synthesis, which induces inflammatory changes in the myocardium, leading to hypertrophy and fibrosis.

Mose et al. (2014) reported that, found indication that cholecalciferol treatment may reduce LVMI and BNP in patients on chronic dialysis, were prospective uncontrolled studies. We hypothesized that daily cholecalciferol supplementation in dialysis patients improves cardiac function and reduces 24-h BP and arterial stiffness. Cholecalciferol caused a marked increase in $\mathrm{p}-25(\mathrm{OH}) \mathrm{D}$ without increased incidence of hypercalcemia or other adverse effects. After six months, no significant differences were observed in $\mathrm{p}$ BNP, cardiac function, 24-h BP or arterial stiffness between groups. Previously, intra-venous 1,25(OH)2D (calcitriol) reduced LV hypertrophy in patients on hemodialysis with elevated p-PTH. Two prospective studies have demonstrated a reduction in LVMI and p-BNP after 6 


\section{HOSSAM M. ABD EL-RAZIK et al.,}

months of cholecalciferol supplementation.

Logistic regression analysis shows that; after applying (Forward method) and entering some predictor variables; the increase in Vitamin D level; had an independent effect on increasing the probability of EF improvement occurrence; with significant statistical difference $(p=0.0005)$. This came in agreement with Wang et al. (2010 and 2012). They reported that, meta-analysis of prospective observational studies showed an inverse association between baseline circulating $25(\mathrm{OH})$ - vitamin D concentrations and risk of CVD with considerable heterogeneity between studies.

\section{CONCLUSION}

Cholecalciferol supplementation in HD patients was safe and efficient to correct hypovitaminosis $\mathrm{D}$ and demonstrated little impact on mineral metabolism. Additionally, there was a reduction in important surrogate markers of cardiovascular risk, namely systemic inflammation and LVH. Vitamin D plays a pivotal role in uremic CVD and its supplementation should be considered even in the absence of mineral metabolism disorders, after hypovitaminosis is detected.

\section{REFERENCES}

1. Bhan I, Burnett-Bowie SA, Ye J, Tonelli M and Thadhani $\mathbf{R}$ (2018): Clinical measures identify vitamin $\mathrm{D}$ deficiency in dialysis. Clinical Journal of the American Society of Nephrology, 5(3):460-7.

2. Bucharles S, Barberato SH, Stinghen AE, Gruber B, Piekala L, Dambiski AC, Custodio MR and Pecoits-Filho R (2012): Impact of cholecalciferol treatment on biomarkers of inflammation and myocardial structure in hemodialysis patients without hyperparathyroidism. Journal of Renal Nutrition, 22(2):284-91.

3. Drechsler C, Pilz S, Obermayer-Pietsch B, Verduijn M, Tomaschitz A, Krane V, Espe K, Dekker F, Brandenburg V, März W and Ritz E (2010): Vitamin D deficiency is associated with sudden cardiac death, combined cardiovascular events, and mortality in haemodialysis patients. European Heart Journal, 31(18):2253-61.

4. Fernández-Ruiz M, Corbella L, MoralesCartagena A, González E, Polanco N, Ruiz-Merlo T, Parra P, Silva JT, LópezMedrano F, San Juan R and Aramendi $M$ (2018): Vitamin D deficiency and infection risk in kidney transplant recipients: A singlecenter cohort study. Transplant Infectious Disease. 20(6): e12988-e12991.

5. Gluba-Brzózka A, Franczyk B, Ciałkowska-Rysz A, Olszewski $R$ and Rysz J (2018): Impact of vitamin $D$ on the cardiovascular system in advanced chronic kidney disease (CKD) and dialysis patients. Nutrients. 10(6):709-711.

6. Jean G, Souberbielle JC and Chazot C (2017): Vitamin D in chronic kidney disease and dialysis patients. Nutrients, 9:328-333.

7. Junarta J, Jha $V$ and Banerjee $D$ (2019): An Insight into The Impact of vitamin D on cardiovascular outcomes in chronic kidney disease. Carlton, (8):781-790.

8. Kim CS and Kim SW (2014): Vitamin D and chronic kidney disease. The Korean journal of Internal Medicine. 29(4):416-420.

9. Major RW, Cheng MR, Grant RA, Shantikumar S, Xu G, Oozeerally I, Brunskill NJ and Gray LJ (2018): Cardiovascular disease risk factors in chronic kidney disease: A systematic review and meta-analysis. PLoS One, 13(3): 192-195.

10. Matias PJ, Jorge C, Ferreira C, Borges M, Aires I, Amaral T, Gil C, Cortez $\mathrm{J}$ and Ferreira A (2010): Cholecalciferol supplementation in hemodialysis patients: effects on mineral metabolism, inflammation, and cardiac dimension parameters. Clinical 
Journal of the American Society of Nephrology,5(5):905-11.

11. Miskulin DC, Majchrzak K, Tighiouart $\mathbf{H}$, Muther RS, Kapoian T, Johnson DS and Weiner DE (2016): Ergocalciferol supplementation in hemodialysis patients with vitamin D deficiency: a randomized clinical trial. Journal of the American Society of Nephrology, 27(6):1801-10.

12. Mose FH, Vase H, Larsen T, Kancir AS, Kosierkiewic R, Jonczy B, Hansen AB, Oczachowska-Kulik AE, Thomsen IM, Bech JN and Pedersen EB (2014): Cardiovascular effects of cholecalciferol treatment in dialysis patients-a randomized controlled trial. BMC nephrology, 15(1):5060 .

13. Pecoits-Filho $R$, Bucharles $S$ and Barberato SH (2012): Diastolic heart failure in dialysis patients: mechanisms, diagnostic approach, and treatment. Seminars in Dialysis, 25(1): 35-41.

14. Pun PH, Lehrich RW, Honeycutt EF, Herzog CA and Middleton JP (2011): Modifiable risk factors associated with sudden cardiac arrest within hemodialysis clinics. Kidney International, 79(2):218-27.

15. Umar M, Sastry KS and Chouchane AI (2018): Role of Vitamin D Beyond the
Skeletal Function: A Review of the Molecular and Clinical Studies. Int J Mol Science, 19(6):1618-1620.

16. Wang L, Manson JE, Song $Y$ and Sesso HD (2010): Systematic review: vitamin D and calcium supplementation in prevention of cardiovascular events. Annals of internal Medicine, 152(5):315-23.

17. Wang L, Song Y, Manson JE, Pilz S, März W, Michaëlsson K, Lundqvist A, Jassal SK, Barrett-Connor E, Zhang $C$ and Eaton CB (2012): Circulating 25-hydroxyvitamin D and risk of cardiovascular disease: a meta-analysis of prospective studies. Circulation: Cardiovascular Quality and Outcomes, 5(6):819-29.

18. Wang Y, Liu Y, Lian Y, Li N, Liu H and Li G (2016): Efficacy of high-dose supplementation with oral vitamin D3 on depressive symptoms in dialysis patients with vitamin D3 insufficiency: a prospective, randomized, double-blind study. Journal of Clinical Psychopharmacology, 36(3):229350 . 
تأثير إعطاء قُيتامين (د) بالجر عات العاليه على وظائف القلب في مرضى الاستصفاء الدموي

حسام محمود عبد الرازق السيد، أحمد علاء الدين أحمد محمد سعد، نبيل فتحي

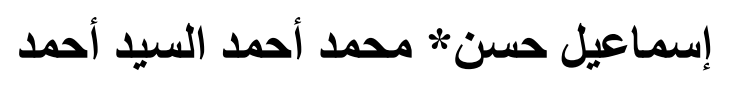

قسمي الأمراض الباطنة والكلى و الباثولوجيا الإكلنيكية* كلية الطب جامعة الأزهر

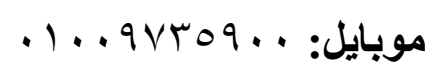

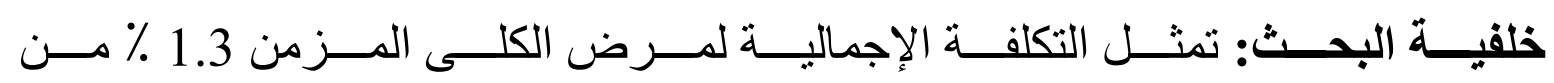

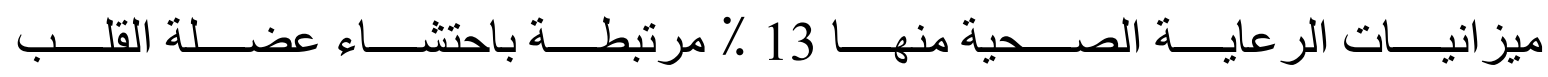
الز ائد و السكتات الدماغية المرتبطة بمرض الكان الكلى المزمن.

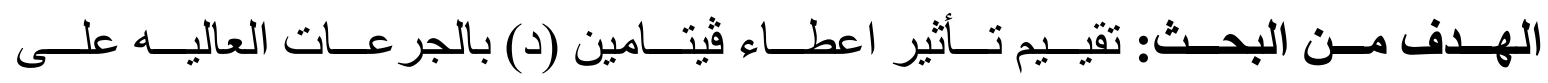
وظائف القلب في مرضى الاستصفاء الدموي.

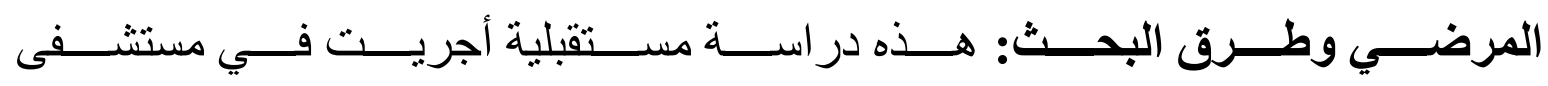

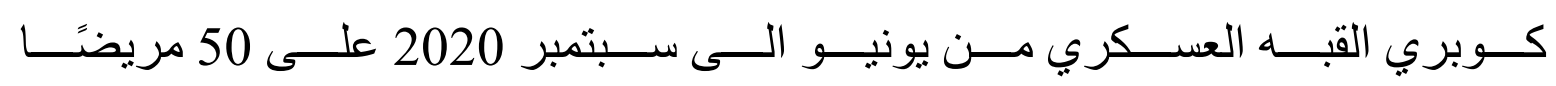

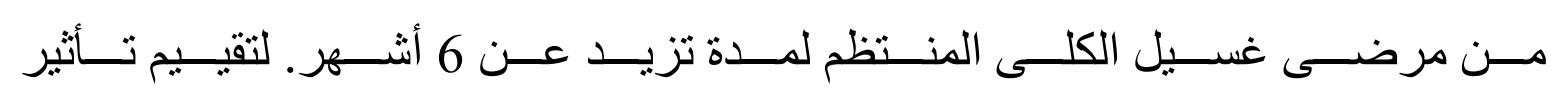

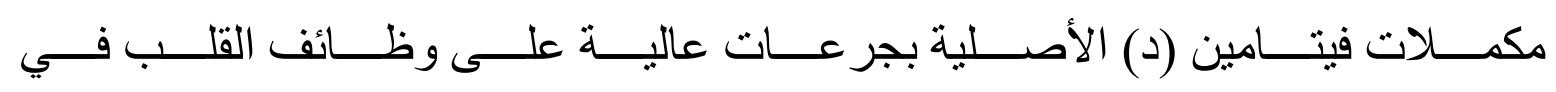

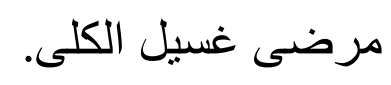

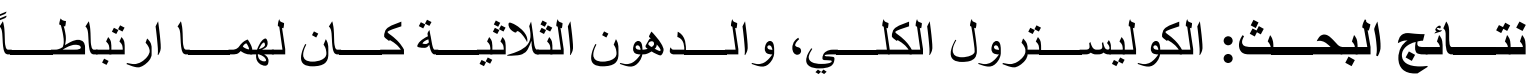

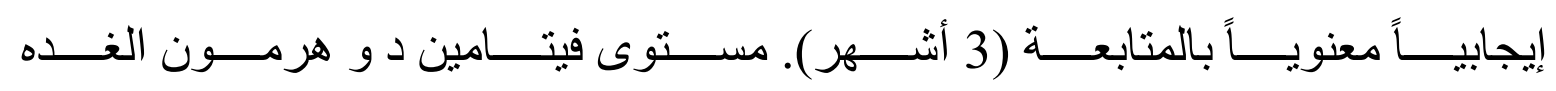

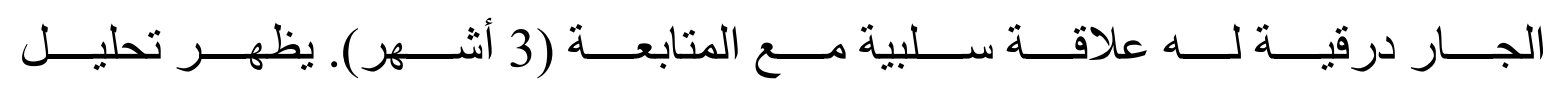

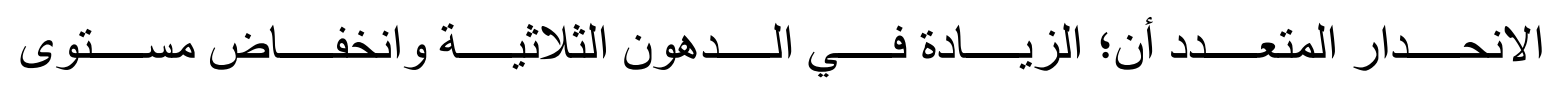

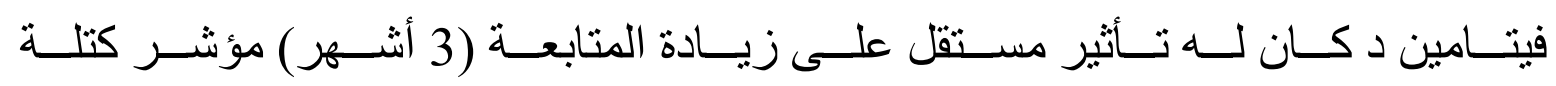

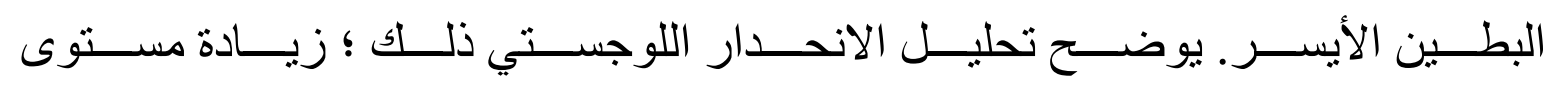


فيتــامين د. كـان لــهـ تـأثير مسـتقل علـى زيــادة احتماليــة حــدوث تحســين كفائسـة القلب.

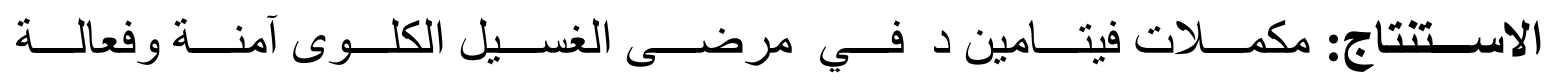

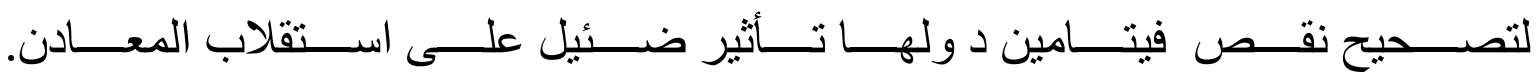

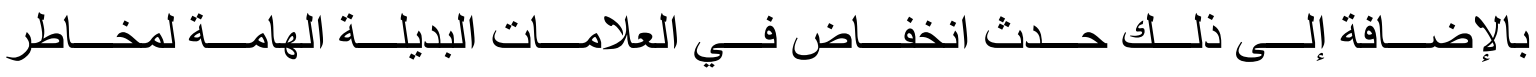

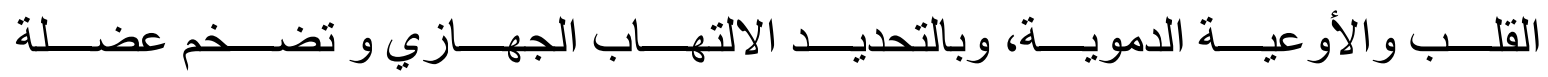

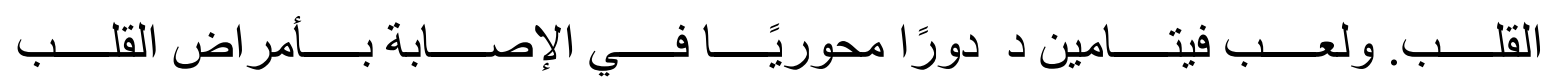

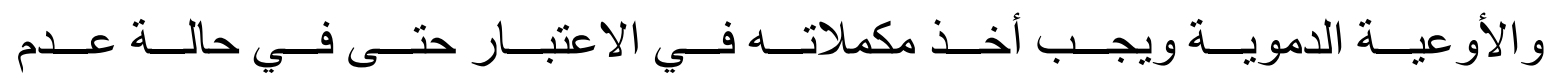
وجود اضطر ابات التمثيل الغذائي للمعادن، بعد اكتثاف نقص الفيتامين. الكلمات الدالة : فيتامين د، وظائف القلب، الاستصفاء الدموي. 